\title{
ПРИМЕНЕНИЕ ПРОГРАММНЫХ ПРОДУКТОВ ARCGIS И ARCVIEW ДЛЯ РЕШЕНИЯ ПРИКЛАДНЫХ ЭКОНОМИЧЕСКИХ ЗАДАЧ
}

\author{
Анна Сергеевна Шумакова \\ Сибирский государственный университет геосистем и технологий, 630108, Россия, г. Новоси- \\ бирск, ул. Плахотного, 10, обучающийся, тел. (923)126-73-65, e-mail: ania.schymakova@yandex.ru
}

\section{Сергей Александрович Вдовин}

Сибирский государственный университет геосистем и технологий, 630108, Россия, г. Новосибирск, ул. Плахотного, 10, кандидат экономических наук, доцент кафедры цифровой экономики и менеджмента, тел. (383)361-01-24, e-mail: german-german@ngs.ru

\section{Елена Викторовна Убоженко}

Сибирский государственный университет геосистем и технологий, 630108, Россия, г. Новосибирск, ул. Плахотного, 10, кандидат экономических наук, зав. кафедрой цифровой экономики и менеджмента, тел. (913)472-36-87, e-mail: ewunsk@yandex.ru

Технология геоинформационных систем стремительно проникла в сферу бизнеса, благодаря наличию средств создания и интеграции баз данных и обеспечению географического анализа. Основной целью исследования является изучение применения программных продуктов ArcGIS и ArcView при решении экономических задач, связанных с развитием цифровой инфраструктуры города Новосибирск. В исследовании были использованы следующие методы: моделирование, прогнозирование, оценка, мониторинг. В статье рассмотрен пример выбора места для открытия магазина и дана оценка решения при этом выборе. Согласно проведенного исследования было выявлено, что данные программы являются важным инструментом при открытии нового магазина.

Ключевые слова: цифровизация, демографические исследования, геоинформационные системы, картографирование, цифровая экономика, данные, технология, информационные системы, принятие решений

\section{APPLICATION OF ARCGIS AND ARCVIEW SOFTWARE PRODUCTS TO SOLVE APPLIED ECONOMIC PROBLEMS}

\section{Anna S. Shumakova}

Siberian State University of Geosystems and Technologies, 10, Plakhotnogo St., Novosibirsk, 630108, Russia, Student, phone: (923)126-73-65, e-mail: ania.schymakova@yandex.ru

\section{Sergey A. Vdovin}

Siberian State University of Geosystems and Technologies, 10, Plakhotnogo St., Novosibirsk, 630108, Russia, Ph. D., Associate Professor, Department of Digital Economy and Management, phone: (383)361-01-24, e-mail: german-german@ngs.ru

\section{Elena V. Ubozhenko}

Siberian State University of Geosystems and Technologies, 10, Plakhotnogo St., Novosibirsk, 630108, Russia, Ph. D., Head of the Department of Digital Economy and Management, phone: (913)472-36-87, e-mail: ewunsk@yandex.ru 
The technology of geographic information systems has quickly penetrated into the business sphere, thanks to the availability of tools for creating and integrating databases and providing geographical analysis. The main purpose of the research is to study the use of ArcGIS and ArcView software products in solving economic problems related to the development of the digital infrastructure of the city of Novosibirsk. The following methods were used in the study: modeling, forecasting, estimation, and monitoring. The article considers an example of choosing a place to open a store and assesses the decision of this choice. According to the research, it was found that these programs are an important tool when opening a new store.

Keywords: digitalization, demographic research, geographic information systems, mapping, digital economy, data, technology, information systems, decision-making

Географические информационные системы - это возможность по-новому взглянуть на мир, который нас окружает. Иными словами, современная технология для анализа объектов реального мира и событий, которые в нем происходят. Технология объединяет работу с базами данных с полноценной визуализацией и анализом пространства [1].

В современном мире без ГИС и технологий не обойтись, они используются во всех сферах деятельности, так как объединяют в себе табличные, текстовые, картографические, статистические и адресные данные. Это возможно благодаря простоте применения этих программных продуктов. ГИС объединяет всю информацию об окружающем мире в единую карту, тем самым упрощая проведение анализа сведений и пространственную визуализацию.

Как не странно, но мы ежедневно сталкивается с их пользованием, например, чтобы заказать такси или продукты, чтобы найти нужный адрес, мы либо включаем навигатор, либо выполняем поиск карт в интернете. Но это всего лишь малая часть функций, которые возможны при использовании ГИС [2]. Так же с помощью их мы можем оценить район, где живем или хотим приобрести квартиру или дом, комплексно оценивая всю инфраструктуру вблизи него, а также отдельное внимание, уделяя просмотру экологических характеристик района.

В России большое количество предприятий ведут разработку геоинформационных систем, создавая все больше и больше программных продуктов. Компания ESRI разработала продукты ArcGIS и ArsView, которые получили широкое распространение по всей России. Они позволяют визуализировать большие объемы информации, создают возможность быстрого анализа этих данных, а также помогают организациям принять верное и быстрое решение [9].

Эти продукты используются не только картографами, они также важны при решении экономических задач, таких как:

- составление плана деловой активности;

- процесс изменения рынка;

- поддержка принятия решений;

- демографические исследования, которые проводятся в целях определения спроса на продукцию [10]. 
Что же еще можно решить с помощью ГИС-технологий? Можно выбрать район и место для нового предприятия, магазина или фирмы, проанализировав близость к потребителям и к поставщикам, а также занятость рабочих мест и конкурентов.

С помощь продуктов ArcGIS и ArcView предприниматели могут решить многие прикладные экономические задачи и вопросы: «Где?», «Кто (или Что?» и «Как?» [8]. Появляется возможность проследить, где живут клиенты, какой у них социальный статус, каковы их потребности и финансовые возможности; разработать точную маркетинговую стратегию и активность, для получения наибольшего результата и отдачи; создать план оптимизации области продаж и подготовить модель последствий принятых решений. А проанализировав целевую аудиторию, это, несомненно, повысит эффективность продвижения услуг или товаров [4].

ArcView - многофункциональное средство анализа сведенных табличных, текстовых и картографических бизнес-данных, демографической, статистической, земельной, муниципальной, адресной и другой информации [6]. Использование этого приложения помогает переориентировать главную цель маркетинговых усилий с удовлетворения усредненных потребностей населения города или района на оперативное реагирование на запросы каждого человека, живущего или работающего в зоне реализации товаров фирмы. Достигаемый при таком подходе принципиально новый уровень сервиса получил наименование персонифицированного маркетинга.

Версии программного продукта ArcView - простые и эффективные средства для визуализации и анализа любых данных об объектах и явлениях. Сферы их применения очень многообразны, начиная от бизнеса, заканчивая промышленностью и экологией [3]. Примером может служить то, что пользователь данного продукта имеет возможность сначала просмотреть данные о продажах товара за предыдущие месяцы в других торговых точках, также посмотреть информацию о социальном составе потенциальных покупателей, оценить план здания, где возможно открытие магазина, а еще и дополнительно сравнить себя с магазинамионкурентами [5]. Например, на карте, как можно увидеть, отмечены места размещения конкурентов, свободные помещения, склады, офисы (рис. 1).

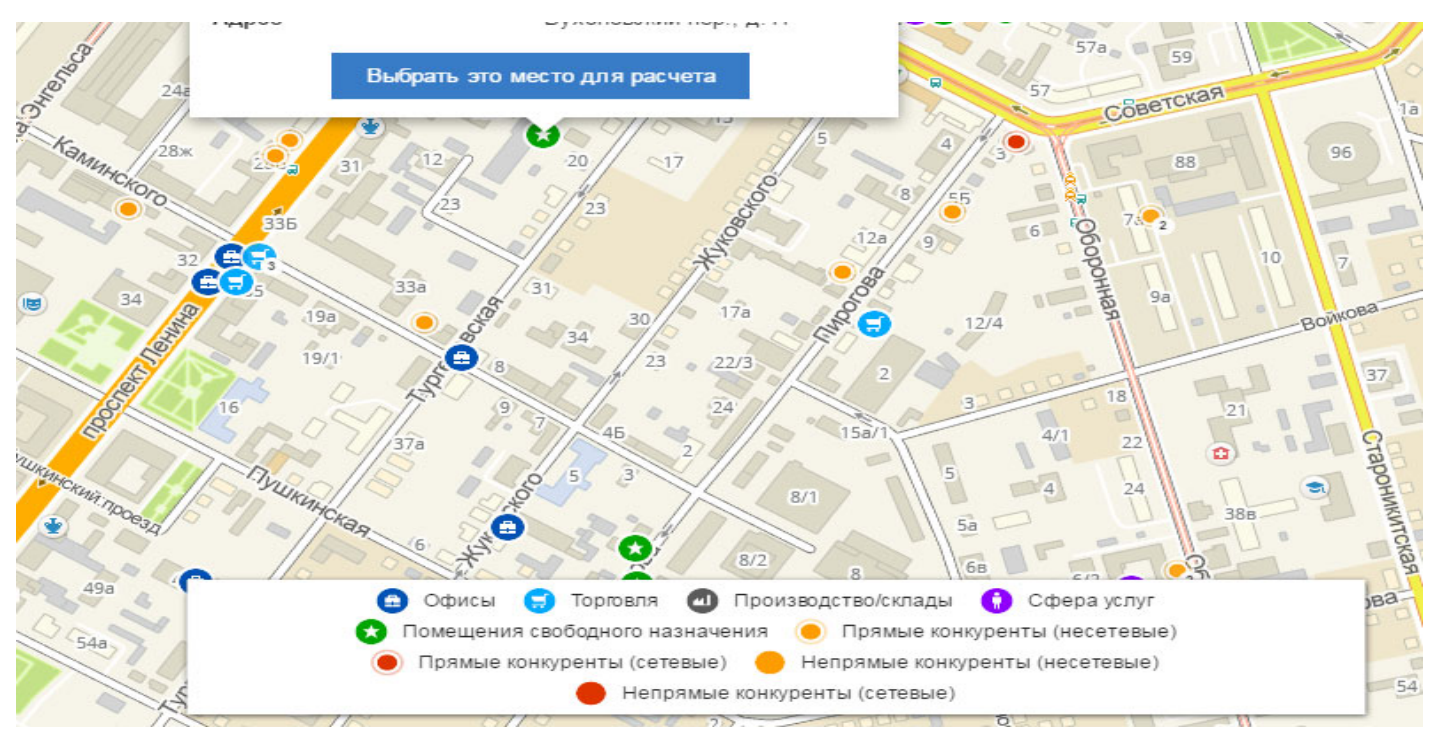

Рис. 1. Карта Новосибирска 
Мы решили «открыть» магазин для мам и новорожденных в городе Новосибирск (рис. 2).

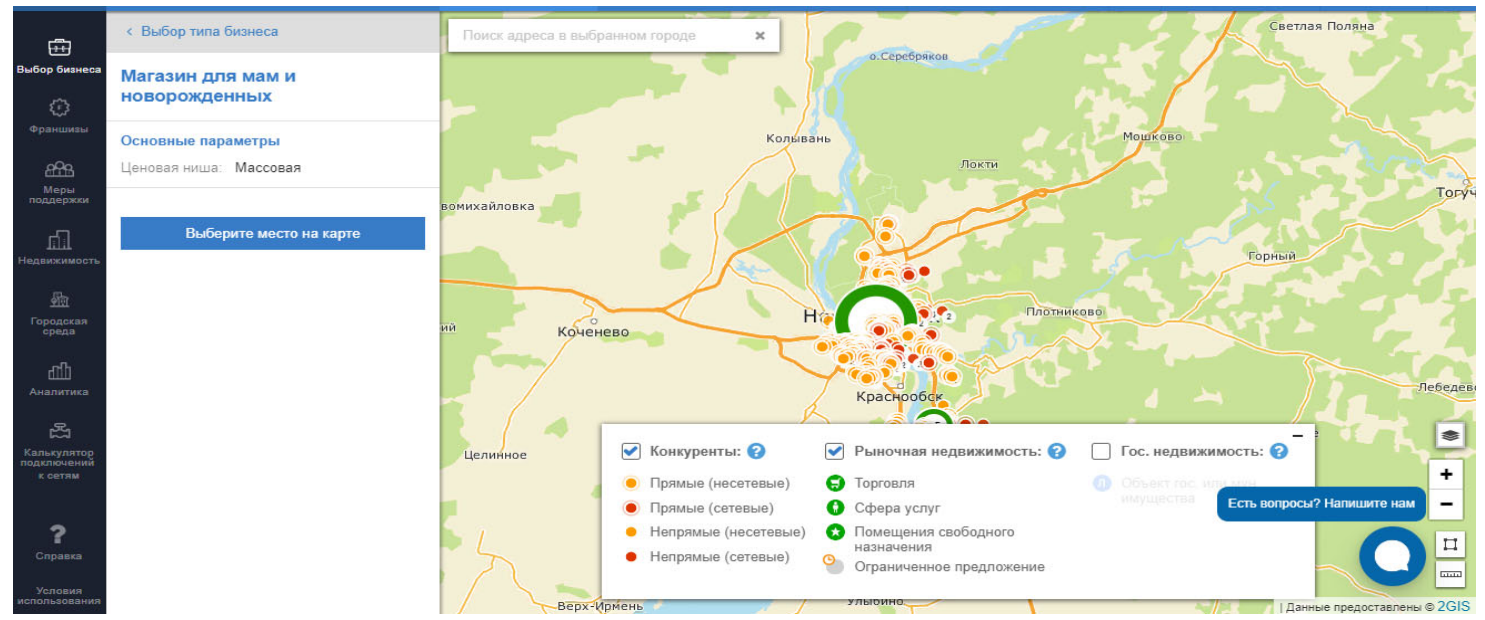

Рис. 2. Выбор места для открытия магазина для мам и новорожденных

Местом для открытия магазина было решено выбрать площадь станции метро К. Маркса. C помощью платформы ArcView был проведет анализ потенциальных покупателей (рис. 3).

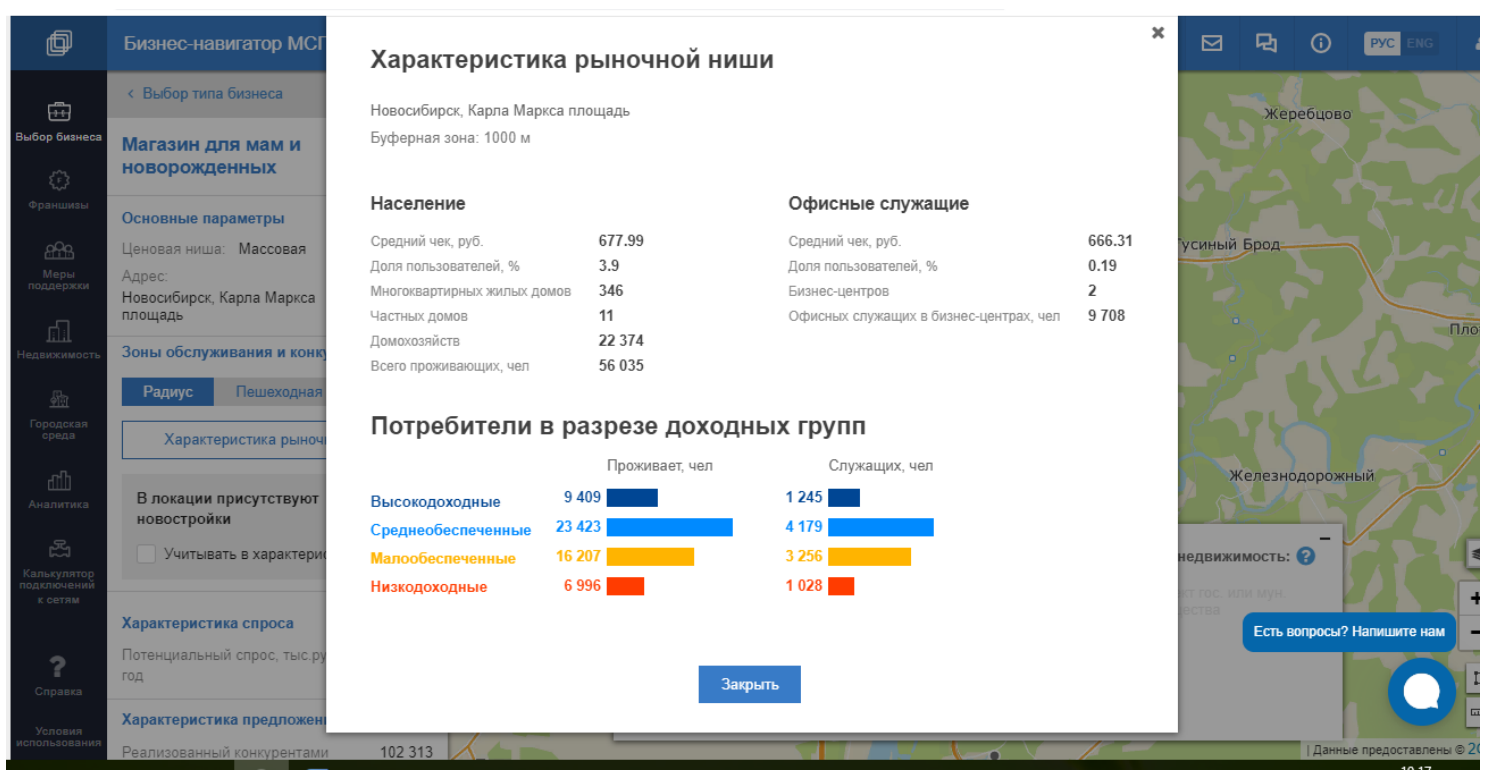

Рис. 3. Характеристика потенциальных покупателей

На рисунке видно, что в данной местности проживают в основном группы людей с малым и среднем уровнем доходов [6]. Исходя из этого на рис. 4 мы видим, что в этом месте открывать магазин не рекомендуется, так как срок окупаемости очень высок, большая арендная плата и большая концентрация конкурентов, что говорит о том, что бизнес в этом месте не принесет прибыли. 


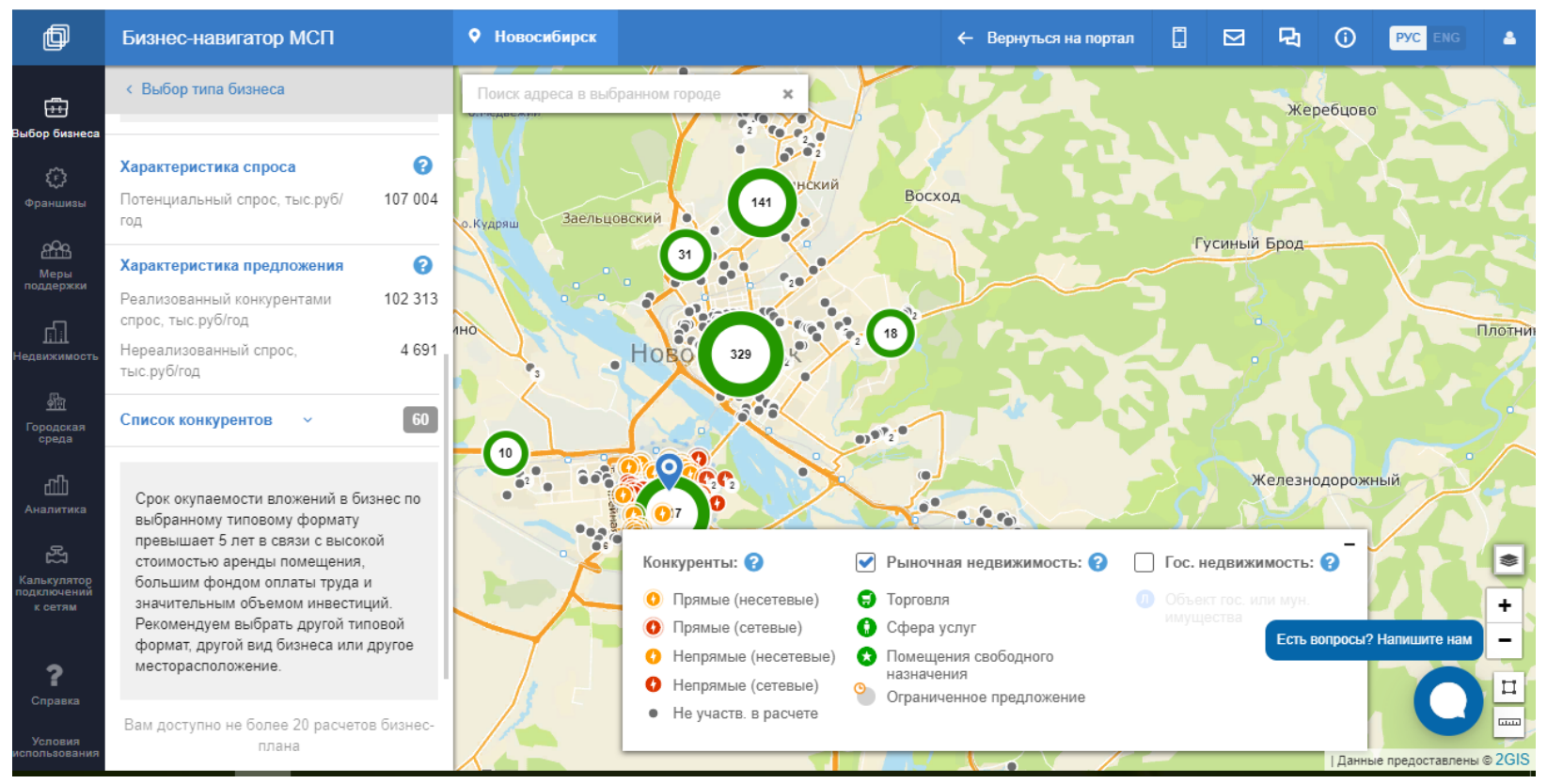

Рис. 4. Результат анализа места для открытия магазина

Итогом этого исследования будет то, что пакет ArcView предоставляет алгоритм процедуры принятия решений, важных для функционирования фирмы. После такого анализа целесообразность открытия магазина не может стать очевидной, либо становится ясно, что надо подбирать другое место или изменить ассортимент товаров и объем товарооборота.

Исходя из вышеизложенного можно сделать вывод, что ArcGIS и ArcView - самые перспективные системы, для решения задач экономики и управления [7]. Структура ГИС настраивается под потребности пользователя.

Таким образом, геоинформационные системы дают широкие возможности для обоснованного принятия оперативных и долгосрочных решений, обеспечивающих устойчивость экономического развития организации. В будущем тематическая карта станет такой же привычной формой представления итоговой деятельности любого предприятия, как сегодня уже стали всевозможные круговые и столбчатые диаграммы.

Главной тенденцией использования ГИС-технологий является использование «прозрачности» ГИС для пользователя, это дает возможность не прибегать к новым дополнительным знаниям, делает работу проще.

\section{БИБЛИОГРАФИЧЕСКИЙ СПИСОК}

1. Борисов А. И. Зарубежная политика управления государственной и муниципальной собственностью // Проблемы и перспективы экономики и управления.: материалы III Междунар. науч. конф. (г. Санкт-Петербург, декабрь 2014 г.). - Спб.: Сатис, 2014. - VI, 76 - 79 с.

2. Вдовин С.А., Убоженко Е.В., Лобанова Е.И. Опыт, проблемы и перспективы стратегий развития цифровой экономики в России и за рубежом // Экономика: вчера, сегодня, завтра. 2019. T. 9. № 1-1. C. 573-582. 
3. Мезенцев, К.Н. Автоматизированные информационные системы: Учебник для студентов учреждений среднего профессионального образования / К.Н. Мезенцев. - М.: ИЦ Академия, 2013. - $176 \mathrm{c.}$

4. Вдовин, В.М. Предметно-ориентированные экономические информационные системы: Учебное пособие / В.М. Вдовин, Л.Е. Суркова, А.А. Шурупов. - М.: Дашков и К, 2016. $-388 \mathrm{c}$.

5. Кошкарев А.В., Геоинформатика в инфраструктурном обеспечении цифровой экономики // Геодезия и картография. - 2019. - Т. 80. - № 1. - С. 119-126. DOI: 10.22389/0016-71262019-943-1-119-126.

6. Рынок ГИС превысит 17,5 млрд. долл. в 2023 г. / Электронный ресурс. Режим доступа: https://sovzond.ru/press-center/news/corporate/4373/ (дата обращения: 09.12.2019).

7. Кулемина, Ю. В. Информационные системы в экономике. Краткий курс / Ю.В. Кулемина. - М.: Окей-книга, 2015. - 112 с.

8. Дубинин М.Ю., Рыков Д.А. Открытые настольные ГИС: обзор текущей ситуации // Информационный бюллетень ГИС-Ассоциации. 2009. № 5(72). С. 20-27.

9. Якубайлик О.Э. Методы построения прикладных геоинформационных систем на основе картографических веб-сервисов геопортала // Труды Международной конференции “Математические и информационные технологии, МІT-2011”. Косовская Митровица, Сербия: Альфа университет, 2011.

10. Геоинформатика: учеб. для вузов: в 2 кн./ под ред. В. С. Тикунова.- 2-е изд., перераб. и доп.- М. : Академия. Кн. 2.- 2012.- 384c.

(C) А. С. Шумакова, С. А. Вдовин, Е. В. Убоженко, 2021 